\title{
Who Ya Gonna Call? Networks of Rural School Administrators
}

\author{
Julie M. Hite \\ Brigham Young University \\ Bart Reynolds \\ Southern Utah University \\ Steven J. Hite \\ Brigham Young University
}

\begin{abstract}
When they need help or advice, who are rural school administrators going to call? Relationships among rural school administrators develop into networks that can affect the success of administrators and their schools. Understanding the structure and content of these networks provides insights into how resources, innovations, and communication flow both within and between rural district administrators. Based on network theory and analysis, this study examines the structure, content, and strategic implications of the administrative networks within and across six contiguous rural school districts in the Western United States. Network graphs are included, illustrating both individual district and the combined six-district rural administrator networks. While acquaintance ties and active work ties are evident both within and across districts, relationally embedded ties and greater cohesion of ties are more evident within districts than across districts. Analyses include consideration of administrative assignment, gender, and geographical location of the network structures. Strategic implications of the network structures and content are discussed.
\end{abstract}

Key Words: Administrative networks, leadership, resources, network theory, school performance

Professional and social network relationships among administrators develop into structures that can affect the success of both administrators and their schools (J. M. Hite, Williams, \& Baugh, 2005; Moolenaar, Daly, \& Sleeters, in press). Understanding these networks can provide a beneficial perspective on the complexity within which educational leaders must function (Sparrowe, Liden, Wayne, \& Kraimer, 2001). Educational leaders intuitively understand the importance of building and maintaining their networks. While many network relationships are formalized in official organizational charts, the majority and often the most commonly used and useful are likely to be intangible and informal, based on the leaders' social networks (Daly \& Finnigan, 2010; Ibarra, 1992; Krackhardt \& Hanson, 1993).

Educational administrators may not be aware of the potentially critical role such informal administrative network relationships often play in their work toward improving schools. They are even less likely to be cognizant of the larger network structure created when these relationships are combined, or of their own structural positions within this administrative network (Snow, Miles, \& Coleman, 1992). Naturally and functionally, leaders in rural education place focus on developing network relationships within their own districts and communities (Harmon \& Schafft, 2009). This administrative focus on the internal district network, without a sufficient focus on building broader networks of cross-district relationships, may be both of particular strategic interest as well as of potential concern for rural school districts (Borgatti \& Foster, 2003; Budge, 2006; J. M. Hite, et al., 2005). With only a few administrators and thus greater need for cross-district collaboration to access information, capabilities, and resources for effective school performance (Awalt \& Jolly, 1999), rural administrators may find it to their advantage to understand how to create or enhance cross-district administrative networks. This study examines the structure and content of administrative networks both within and across six rural school districts and identifies potential strategic implications of these relationships among rural school administrators. 


\section{Theoretical Framework}

The study of organizational networks focuses on the interpersonal and professional relationships and structures of organizations such as schools or districts. Network methods identify these network structures, and network theory seeks to explain both the influences on and strategic outcomes of these networks (Borgatti \& Foster, 2003; Brass, Galaskiewicz, Greve, \& Tsai, 2004; Kilduff \& Tsai, 2003; Scott, 2000). For example, in the context of rural education, network analysis can focus on the structure of administrator relationships within a school district or between school districts. By identifying these structures, network theory can explain potential strategic outcomes in terms of school performance and student learning.

\section{Network Structure}

The relationship between two rural school administrators creates a dyadic link or tie between them: For example, the relationship between David and Charles is such a tie. David, a rural elementary school principal, has a good friend he can always call: Charles, a vice principal at a nearby high school. David and Charles went to high school together many years ago at the high school where Charles is now vice principal. They are currently next door neighbors, and their children play on the same soccer teams. They were both teachers at the elementary school where David, who is now the principal, was the $5^{\text {th }}$ grade teacher for Charles's son. However, on the organizational chart, no formal connection or functional integration exists between their present administrative assignments.

Ties can exist between administrators within the same district or across districts. The set of an administrator's direct ties with other administrators creates a direct network structure, which can be visualized as a star with the administrator in the middle. Figure 1 illustrates a direct network with David in the middle. Any administrator may place himself in the center of this network and consider those with whom he has direct ties.

When the ties among the administrators with whom David has ties are included in the structure, an egocentric network is created in which David is still in the center (see Figure 2). When the egocentric networks of many administrators are combined, such as when including each administrator in the district, an even larger network structure is created within which each administrator occupies a specific position (Carrington \& Scott, in press; J. M. Hite, et al., 2005; Scott, 2000).

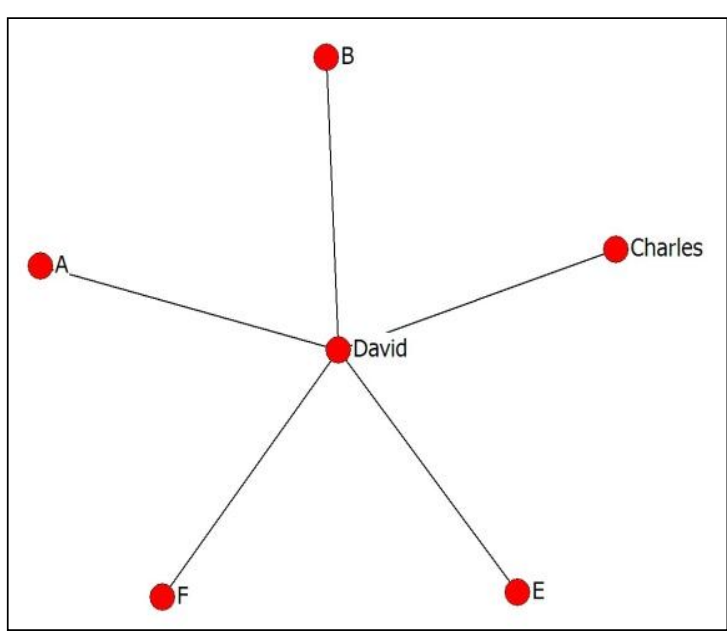

Figure 1. Direct network.

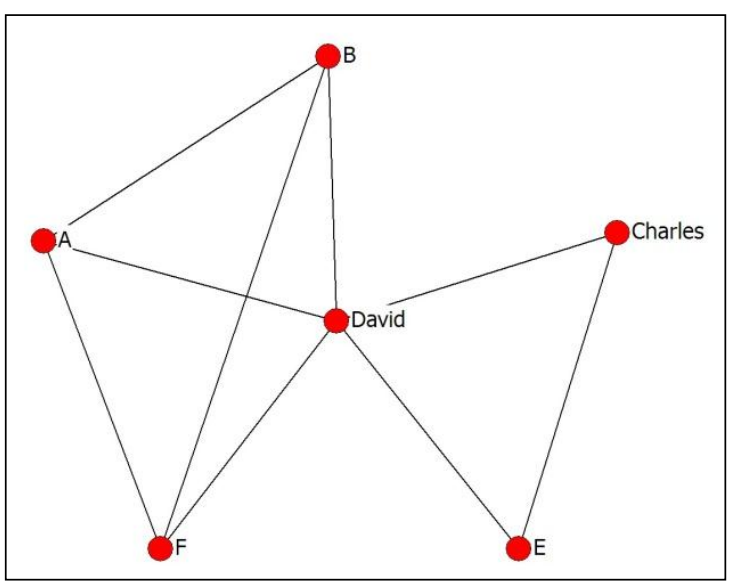

Figure 2. Egocentric network.

Whereas Figures 1 and 2 indicate David as being central, in the larger combined administrative network Charles has a much more central position than David (see Figure 3). Both the structure of the larger network and administrator positions within this network can have strategic implications for the performance of these administrators and their schools.

An administrator's position within the larger network can be described in terms of its centrality and whether it fills structural holes in the network. Both centrality and filling structural holes have strategic implications for the administrator's ability to influence the network and to draw upon the resources that flow through the network. 


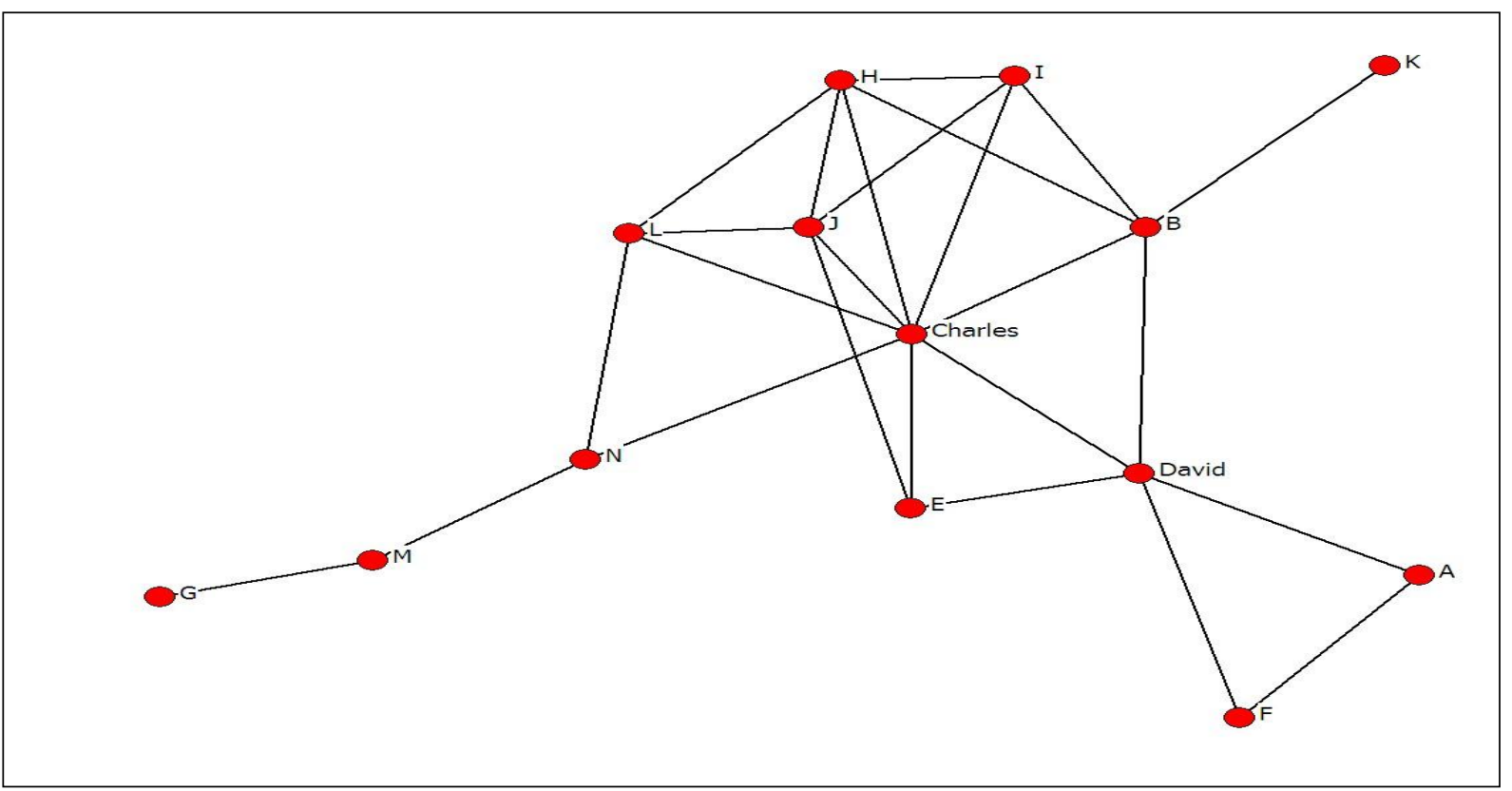

Figure 3. Example of a whole network.

Administrator centrality is defined by the number of ties an administrator has within the network: The greater the number of ties, the greater the centrality (Bonacich, 1987; Borgatti, 2005; Freeman, 1979; Scott, 2000; Wasserman \& Faust, 1994). For example, if David has ties with 5 other administrators while Charles has ties with 8, then Charles would have a more central position (greater centrality) in the larger network (see Figure 3). Greater centrality may provide an administrator with better communication within the larger network, more control over resource flows, greater visibility and prestige, and more ability to generate new ties (Borgatti, 2005; Daly \& Finnigan, 2010; Ibarra, 1993; Pappas \& Wooldridge, 2007). Greater centrality also suggests that an administrator may have better access to a wider variety of external resources to facilitate the school's performance.

Individual administrators' positions in a network can also be defined by the extent to which they fill structural holes in the network (Burt, 2002). When an administrator has a tie that creates a link to a nonor less-connected part of the network, this tie fills a structural hole in the network and places the administrator in a "brokering" position (see Figure 4 ). For example, if David is the only administrator in his district with a tie to another district, then David is in a brokering position between these two districts and fills a structural hole in the network. If this tie is broken or lost, the two districts would have no other network connection. In this structural position, David functions as a gatekeeper and, as a result, may be more aware of and have better access to additional resources and also have a greater ability to influence the larger network than other administrators in his district. Thus David's position in the larger network may have strategic implications for the performance of his school and his district.

\section{Network Content}

Each tie in a network functions as a conduit or bridge for the flow or exchange of different kinds of network content between these administrators. For example, when David shares information with Charles, this information flows across the direct tie to Charles. If Charles also shares information with David, then their tie provides the means for a twoway exchange of information. Network ties can be described by the type of content that flows across them (Borgatti, 2005; Scott, 2000). For example, the network literature examines communication networks, friendship networks, and advice networks. When a tie carries multiple types of content, this tie can become a more critical network relationship (J. M. Hite, 2008; J. M. Hite, et al., 2005). For example, the tie between David and Charles carries not only friendship, personal advice, and emotional support, but also educational advice, resources and ideas. As a result of their many exchanges over time, the tie also carries norms of reciprocity, favors, and trust. Such ties with multiple content flows can have a particularly important strategic role for schools and districts, including resource acquisition, information seeking, and establishment of legitimacy (Elfring \& Hulsink, 2007). Network theory seeks to explain the 


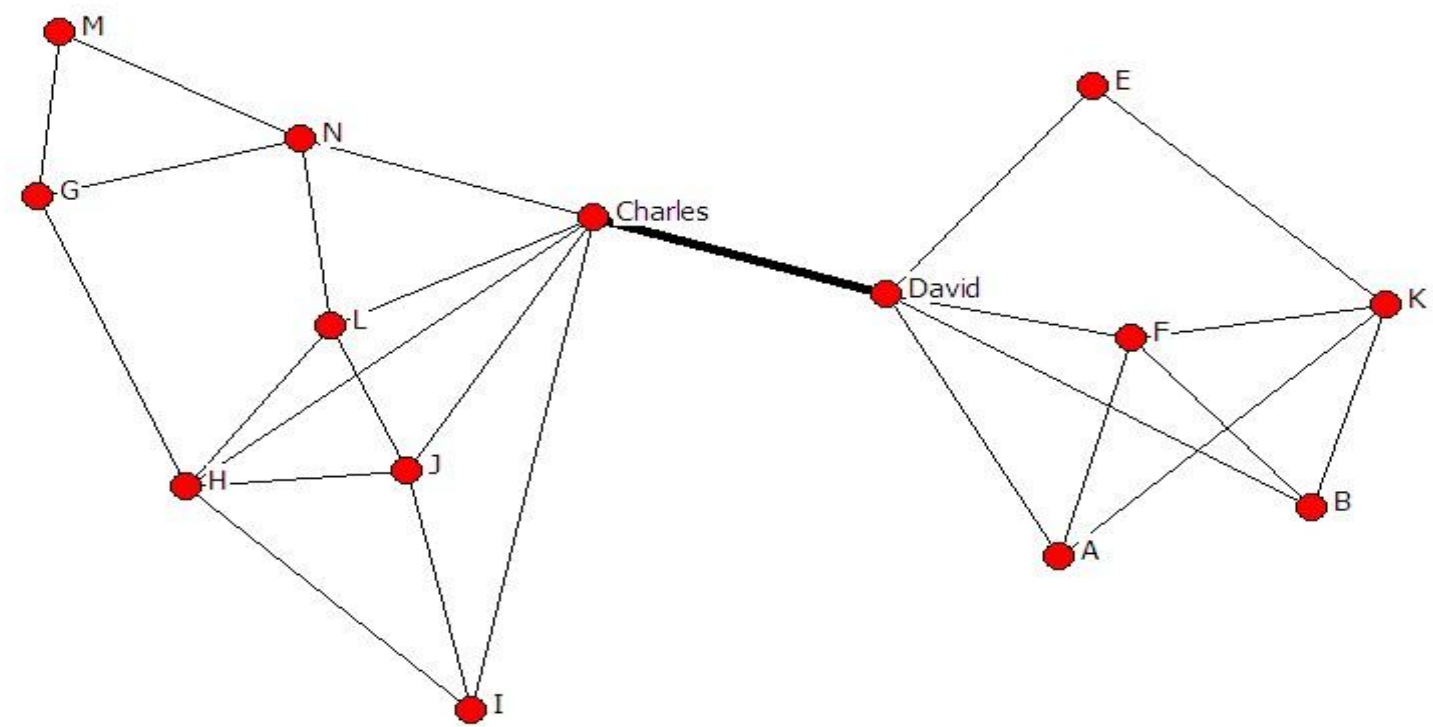

Figure 4. Example of a tie spanning a structural network hole.

Multiple network structures can exist within the same set of school administrators, each network structure facilitating the flow of a different type of content. For example, different networks can facilitate flows for resources, social/emotional support, and/or innovation (J. M. Hite, et al., 2005).

Network content can have important strategic implications for school administrators. One type of critical network content is the extent of relational embeddedness within a tie. Relational embeddedness is defined as a tie embedded within a social relationship. Relationally embedded ties are generally stronger than other ties and demonstrate stronger personal relationships, greater trust, more work-based interaction, more detailed information transfer, greater social capital, and more reciprocity (Granovetter, 1985; J. M. Hite, 2003, 2005; Uzzi, 1996). As a result, information flow and resource access are often enhanced in these types of ties (Borgatti \& Cross, 2003) and, consequently, administrators are better able to influence and support each other. Given the increased trust in these network relationships, administrators with relationally embedded ties can better work together, share resources, solve problems, and facilitate each other's administrative success. In the case of David and Charles, they would be highly likely to consult with each other on sensitive problems or other work

issues that require confidentiality. In contrast, a tie with lower relational embeddedness may be characterized as an acquaintance or exclusively workrelated tie without the same extent of a social relationship as can be found within a relationally embedded tie (Granovetter, 1973, 1985, 1992). While ties that are not relationally embedded can be very functional and effective, they operate under lower levels of trust within the tie. For example, David would be less likely to confide in another administrator who represents only an acquaintance tie than he would in Charles.

The tie between David and Charles represents high relational embeddedness. These two administrators know each other very well and interact frequently in diverse contexts, which help them to understand each other's problems, and enjoy social capital in terms of exchanging favors and knowing people in common. This type of network tie can provide critical opportunities for sharing and solving problems within a confidential, trusting relationship. High relational embeddedness contributes to three different types of trust in the relationship (J. M. Hite, 2003). First, the personal relationship builds personal trust in which both administrators have each other's 
interests at heart. Second, high interaction builds competency trust in which both administrators know that the other is highly capable, which facilitates effective interaction. Third, social capital generates increased social trust in which the administrators have common norms of reciprocity and sharing, acknowledge their social obligations to each other, and know some of the same people, which helps to assure their trust in each other. Such multidimensional trust, resulting from relational embeddedness in a network tie, can provide many advantages for school administrators, benefiting both their schools and students (J. M. Hite, 2003).

\section{Strategic Implications of Network Structure and Content}

Administrator network ties, the content of these ties, and the resulting structural position of administrators within the larger network can facilitate the accomplishment of educational goals (e.g. Daly \& Finnigan, 2010; Dyer \& Singh, 1998; J. M. Hite \& Hesterly, 2001; J. M. Hite, et al., 2005). For example, network relationships within districts can affect internal resource acquisition and allocation, information flow, knowledge management, teaming, collaboration, influence, trust, vision diffusion, and ability to foster support for organizational learning and change (Kahne, O'Brien, Brown, \& Quinn, 2001; Raider \& Krackhardt, 2002; Tsai, 2001). Similarly, cross-district networks can also affect resource flows, breadth of range for resource acquisition, information access, innovation, organizational learning, boundary spanning, political influence, and the ability of a school to strategically manage pressures within the external environment (Elfring \& Hulsink, 2007; J. M. Hite \& Hesterly, 2001; Hoang \& Antoncic, 2003; Honig, 2006). Thus network theory suggests that rural schools can be strategically influenced by the structure and content of administrator network relationships. So David's high school can benefit or be hindered by the types and numbers of David's network ties and his consequent position within the larger administrative network.

However, administrators often fail to comprehend the structure, content, and potential benefits of the networks to which they do or could belong. While administrators intuitively understand that they contact different people to accomplish different purposes and that they need to build and maintain their informal networks, these networks often consist of close contacts whom they prefer to seek out or people with whom they have had previous contact (Gulati, 1995). As a result, other critical relationships and resources may be overlooked and remain untapped, although they would benefit the school. Additionally, educational administrators may pay more attention to the more obvious formal organizational relationships and neglect important potential informal network ties and bridges both within and across districts (Borgatti \& Foster, 2003; J. M. Hite, et al., 2005).

\section{Networks in Education}

Network literature has recently begun to address the role and functions of organizational networks in the context of educational leadership (e.g. J. M. Hite, et al., 2005; J. M. Hite, Williams, Hilton, \& Baugh, 2006; Kahne, et al., 2001; Wohlstetter, Malloy, Chau, \& Polhemus, 2003). However, only a few studies have examined educational networks using network methods and analysis techniques common in sociology, management, and organizational theory. For example, using network methods Granovetter (1986) examined school desegregation, and Friedkin and Slater (1994) assessed principal centrality. Moody (2001) examined the role of school integration on students' friendship networks. J. M. Hite, Williams, and Baugh (2005) found multiple network structures among the same set of administrators, and J. M. Hite, Williams, Hilton, and Baugh (2006) found administrator characteristics related to centrality within an innovation network. More recently, network research in educational settings is beginning to address the implications of network structures (e.g. Daly \& Finnigan, 2010; Moolenaar, et al., in press). Most network studies in education incorporate general network ideas and address the advantages of maintaining networks and building relationships. For example, in rural networks, cross-district collaboration was found to be facilitated through administrative networks (Furtwengler, Furtwengler, Turk, \& Hurst, 1997). Rural education presents a fundamentally different strategic context than urban education. Specifically, rural school districts typically have fewer students and fewer administrators, spread across larger geographical areas than urban districts. What is not known is how this "smaller but larger" rural context may affect administrative networks. Networks of administrators within rural districts can be expected either to have dense network structures due to typically fewer administrators or to have sparse network structures due to large or difficult geographical distances between those administrators (Browne-Ferrigno \& Allen, 2006; Budge, 2006; S. J. Hite, J.M. Hite, Mugimu, \& Rew, 2007). Similarly, administrator networks across rural districts may be expected to demonstrate dense network structures 
because limited internal resources may force administrators to reach across district boundaries for information, capabilities, and resources (Honig, 2006; Mizruchi \& Galaskiewicz, 1993) or to demonstrate sparse structures because large or difficult geographic distances between administrators, and the cultural difference that can result, may again result in fewer network ties (Browne-Ferrigno \& Allen, 2006; Budge, 2006; S. J. Hite, et al., 2007).

This study uses network theory and analysis to examine and describe the structure and content of administrative networks within and across six rural districts. The study also seeks to explain the potential strategic implications of these network structures and content for the rural districts and their administrators as they seek to improve the performance of their schools in facilitating student learning.

\section{Methods}

Using network methods and analysis, this study identified the ties between administrators within and across six rural districts to create the structure of the larger administrative network. Network theory and methods guided the sampling, data collection and analysis procedures (e.g. Carrington \& Scott, in press; Hanneman \& Riddle 2005; Scott, 2000).

\section{Network Population}

The study included administrators from six geographically contiguous rural public school districts (denoted A, B, C, D, E, and F) in the western United States, covering approximately 18,246 square miles and serving 55 schools and 17,146 students (see Table 1). The six districts cover five counties, with four of the districts each representing an entire county and two districts (D \& F) both being located within the same county. District E, the largest district in terms of student population, has the most administrators and the most female administrators. Geographically, Districts B-F are similar; however, District A is separated from the other districts by a mountain range, resulting in it being historically somewhat isolated and thus experiencing some differences in cultural development (e.g. BrowneFerrigno \& Allen, 2006; Budge, 2006). All the districts have access to the same cross-district curriculum support program and also compete at the same athletic level. The main highway runs southwest to northeast through Districts D, E and F.

Table 1

Six Rural School Districts

\begin{tabular}{|c|c|c|c|c|c|}
\hline District & $\begin{array}{c}\text { Size in } \\
\text { Square Miles }\end{array}$ & $\begin{array}{c}\text { Intersects Main } \\
\text { Highway }\end{array}$ & $\begin{array}{c}\text { Number of } \\
\text { Administrators }\end{array}$ & $\begin{array}{c}\text { Number of } \\
\text { Schools }\end{array}$ & $\begin{array}{l}\text { Student } \\
\text { Population }\end{array}$ \\
\hline $\mathrm{A}$ & 4,439 & No & 13 & 10 & 2,256 \\
\hline B & 3,412 & No & 8 & 5 & 2,244 \\
\hline $\mathrm{C}$ & 6,818 & No & 9 & 10 & 2,829 \\
\hline $\mathrm{D}$ & 633 & Yes & 10 & 7 & 2,329 \\
\hline $\mathrm{E}$ & 1,976 & Yes & 18 & 16 & 4,511 \\
\hline $\mathrm{F}$ & 968 & Yes & 11 & 7 & 2,995 \\
\hline Total & 18,246 & 3 & 69 & 55 & 17,146 \\
\hline
\end{tabular}

Using network methods, the initial study population in these six districts was 70 school and district administrators. Administrators were defined as those persons functioning in administrative capacities within the districts and having received state administrative licensure. These administrators all had either a master's or doctoral degree in an education-related field. Using network census sampling, this study collected data from 69 of the 70 members of this population (see Table 2). Although one principal declined to participate, the response rate of $98.5 \%$ is well above the generally accepted response rate of $80 \%$ needed for network studies with directional ties to minimize effects of missing data on the network structure (Costenbader \& Valente, 2003). 
Table 2

Administrators by Rural District, Position and Gender

\begin{tabular}{|c|c|c|c|c|c|c|c|}
\hline \multirow[b]{2}{*}{$\begin{array}{l}\text { Rural } \\
\text { District }\end{array}$} & \multicolumn{2}{|c|}{$\begin{array}{c}\text { Superintendent / } \\
\text { Assistant Superintendent }\end{array}$} & \multicolumn{2}{|c|}{$\begin{array}{l}\text { District } \\
\text { Director }\end{array}$} & \multicolumn{2}{|c|}{$\begin{array}{c}\text { Principal / } \\
\text { Assistant Principal }\end{array}$} & \multirow[b]{2}{*}{ Total } \\
\hline & Male & Female & Male & Female & Male & Female & \\
\hline $\mathrm{A}$ & 1 & 0 & 4 & 0 & 7 & 1 & 13 \\
\hline B & 1 & 0 & 2 & 0 & 4 & 1 & 8 \\
\hline $\mathrm{C}$ & 1 & 0 & 1 & 0 & 6 & 1 & 9 \\
\hline $\mathrm{D}$ & 1 & 0 & 1 & 1 & 6 & 1 & 10 \\
\hline $\mathrm{E}$ & 2 & 0 & 2 & 0 & 7 & 7 & 18 \\
\hline $\mathrm{F}$ & 2 & 0 & 1 & 1 & 6 & 1 & 11 \\
\hline Total & 8 & 0 & 11 & 2 & 36 & 12 & 69 \\
\hline
\end{tabular}

\section{Data Collection}

The researchers obtained permission from each superintendent to invite the administrators in their district to participate in the study during the late fall of the school year. The superintendents also provided the researchers with a letter of introduction indicating their support of the research. Researchers then contacted each administrator via telephone to describe the study, invite their participation and set up an appointment for one of the researchers to meet with them at their office to personally administer the network survey.

The 69 administrators each met individually with one of the researchers for about an hour. During these meetings, researchers provided the administrators with a copy of the superintendent's letter of support, clarified that participation was voluntary, and obtained their permission to participate. The researcher then personally administered the demographic and network surveys The strategies of first obtaining district approval and support and then personally inviting and meeting with each administrator were crucial to obtaining such a high response rate.

The network survey provided a census listing of all administrators across all six districts. The administrators first identified the other administrators whom they knew and with whom they interacted. This egocentric network process identified the dyadic network ties of each administrator. The 69 administrators identified an average of 28 ties ( $\mathrm{SD}=$ 7, range 7-34) for a total of 1,290 dyadic ties (network density $=28 \%$ ). Each administrator then answered three relational embeddedness questions for each of their indicated ties. The first question addressed their personal relationship and asked how well they knew each administrator personally from

"don't know them" to "know them very well/close friend." The second question addressed their dyadic interaction, asking how frequently they had contact with each administrator (phone, email, mail, face-toface), selecting from none, occasionally, monthly, weekly, or daily. The third question addressed their social capital, asking whether they perceived they could easily ask each administrator a "big favor" (J. M. Hite, 2003). The first two questions related to actual behaviors, while the third related to potential behavior.

\section{Data Analysis}

A strength of relational embeddedness score for each tie was obtained by summing the network survey data. As expected, the very low end of the range was not well represented, validating that the informants did indeed know their ties. That is, none of the informants initially indicated that they knew and interacted with someone and then marked that they "don't know them" on the network question. Thus, the low end of the range (where there were no responses) was dropped and the remaining responses fell within a 10 point range. Using the 10 -point range, ties were then identified as acquaintance ties (strength range $1-4 ; n=380$ ), active work ties (strength range 5-7; $\mathrm{n}=534$ ), or relationally embedded ties (strength range $8-10 ; n=386$ ).

Network data, including tie, tie strength, and actor attribute data, were then imported into UCINet software (Borgatti, Everett, \& Freeman, 1999) to create the network matrix and support graphical mapping of the network with NetDraw software 
(Borgatti, 2003). Thickness of the ties in the graphical mapping represents the strength of the tie in terms of relational embeddedness. The analyses of these network graphical maps then focused on evaluating network structure (size, centrality, clustering, core/periphery, cohesion, and structural holes) and content (relational embeddedness) of the network at multiple levels, including administrator egocentric networks, district networks, and the combined six-district network. Administrator attributes of district, gender, type of school and position were displayed on the graphical maps by the shape, shading and size of the network nodes. ArcGIS software was used for the geographical mapping of the administrators' schools, which facilitated the combining of social and geographical space.

\section{Findings}

The larger network structure of all administrators indicates both within-district clustering and acrossdistrict ties. Each district has connections with each of the other districts (see Figure 5). This multiple district network indicates that one district is more peripheral than the others. The administrators in this peripheral district were not as well connected across districts as were the administrators in the other five districts.

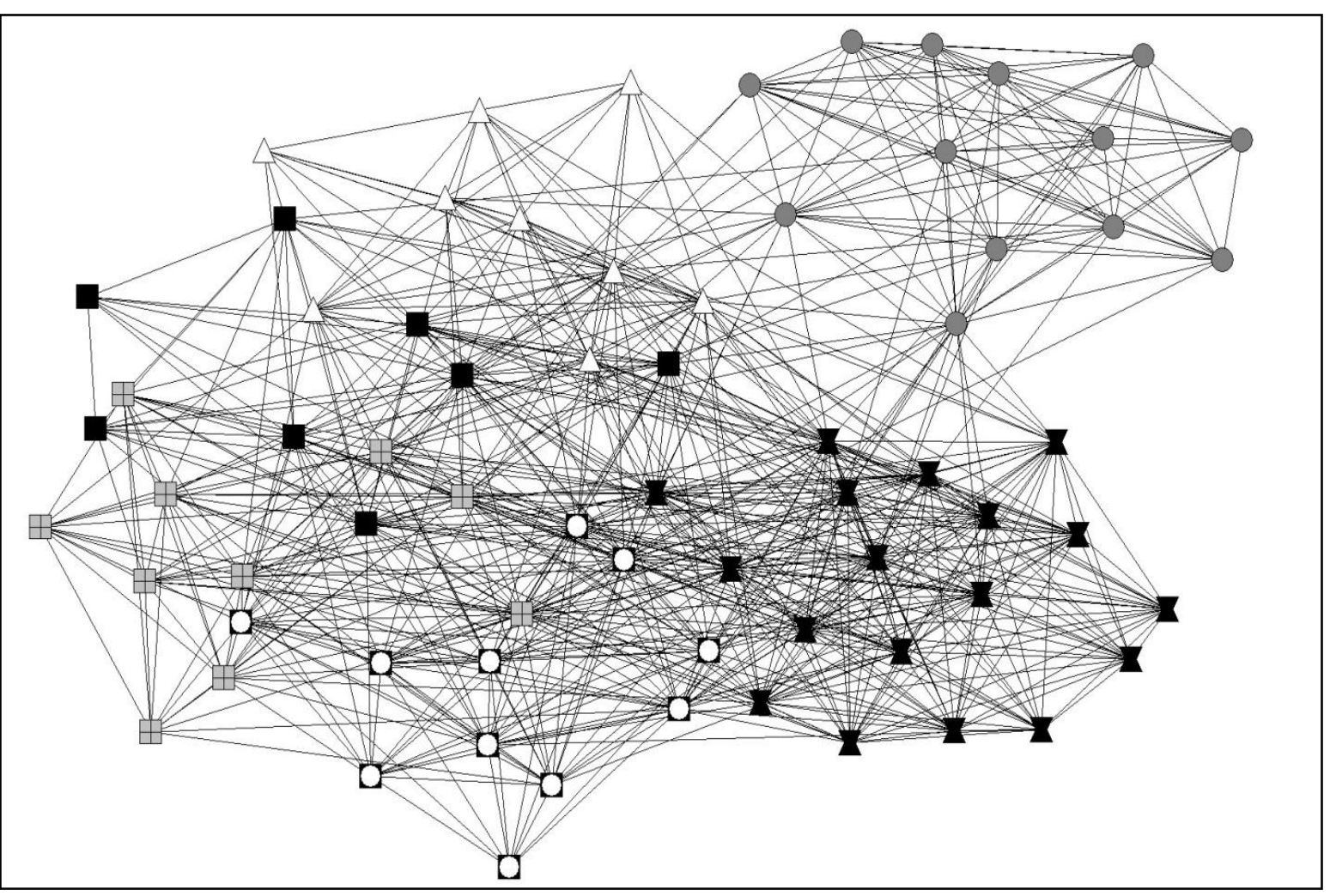

Figure 5. Inter-district administrative network: The whole network.

Key: Each district is represented by a different shade/shape combination.

This network graph in Figure 5 represents all ties without consideration of the network content or extent of relational embeddedness. However, when the content of these ties in terms of relational embeddedness is taken into account, a more distinct structural pattern of within-district cohesion emerges. Graphical network maps of the acquaintance ties (tie strengths of 1-4) and the active work ties (tie strengths of 5-7) both reflect structural patterns similar to the whole network map in Figure 5. Yet, in contrast, the graphical network map of only the relationally embedded ties (tie strengths of 8-10) demonstrates very obvious within-district clustering and only a few ties across districts (see Figure 6). This greater cohesion within-districts than across districts indicates that ties within the districts were more likely to be relationally embedded than those across districts. Figure 6 also demonstrates that all administrators had relationally embedded ties. 


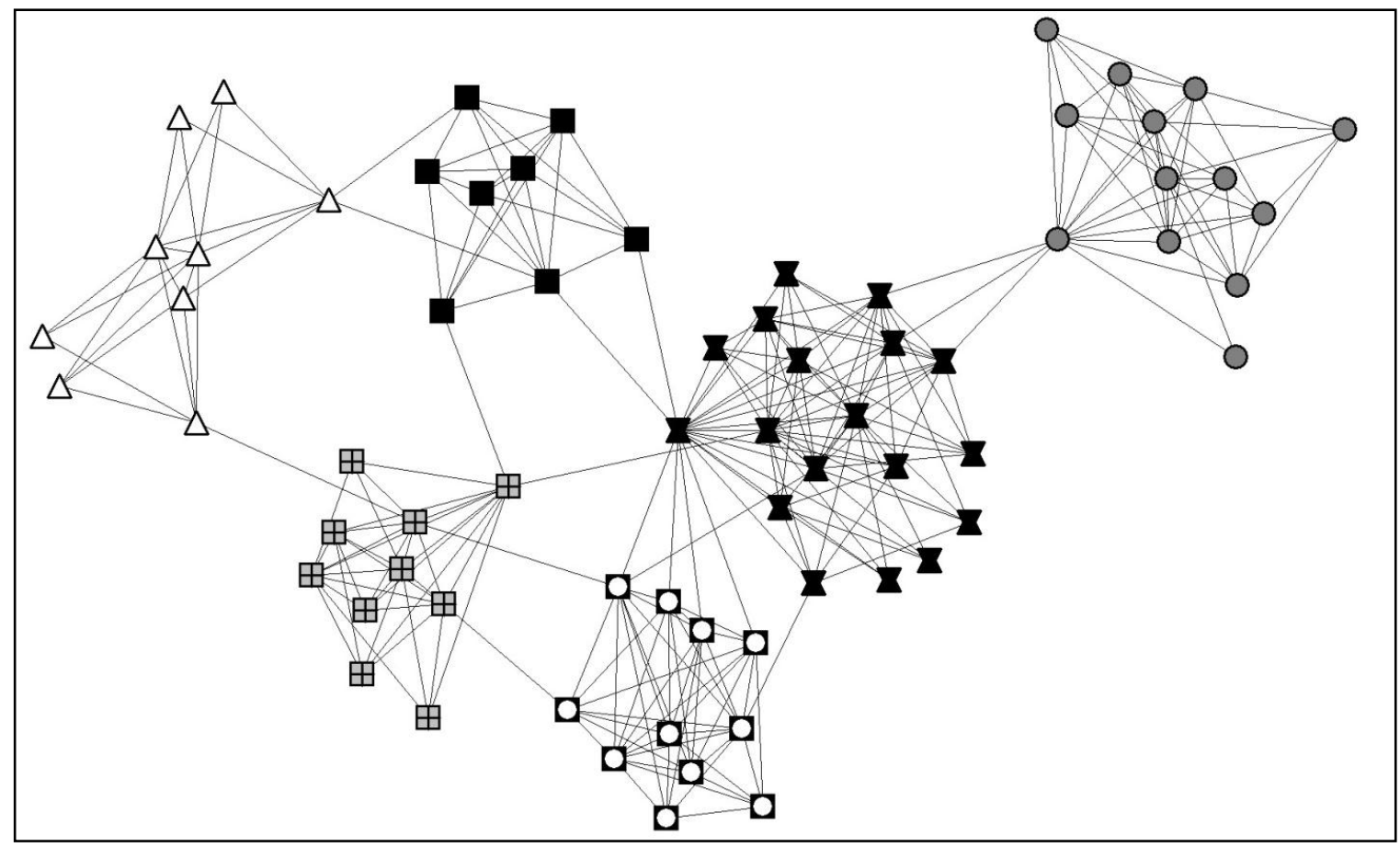

Figure 6. Inter-district administrative network: Relationally embedded ties. Key: Each district is represented by a different shade/shape combination.

District centrality in this network of relationally embedded ties was a function of the number of boundary spanners between districts. While each district had at least two cross-district relationally embedded ties, the peripheral district in Figure 5 is still peripheral in Figure 6. This district had relationally embedded ties to only one other district, facilitated by only one single administrator. In contrast, the most central district had relationallyembedded ties to four of the other five districts, facilitated by five different administrators. This central district had more administrators functioning as boundary spanners, thus increasing the number of cross-district ties, which in turn increased the centrality for this district within the network.

The cross-district network structure of relationally embedded ties also allows for examination of which administrators functioned as boundary spanners. The $23(33 \%)$ administrators who functioned as cross-district boundary spanners were spread across all types of schools and assignments, with $5(22 \%)$ at elementary schools, 3 (13\%) at middle schools, $9(39 \%)$ at high schools, and $5(22 \%)$ at district offices. The majority of boundary spanners $(69 \%)$ were principals. While most boundary spanners between districts were male administrators $(83 \%)$, this gender pattern likely reflects the larger pattern of there being more males in these administrative positions in general.

The structure of this network of relationally embedded ties also indicates that female administrators were generally peripheral within their districts. Figure 7 illustrates the position of female administrators $(20 \%)$ within this network structure. Twelve of the female administrators were principals/assistant principals, two were district directors, but none were superintendents or assistant superintendents. Of the 14 female administrators, 12 $(86 \%)$ were found to be on the periphery of their own district network structures indicating that they were not central within this set of strong, relationally embedded ties. Five of the six districts had only 1 or 2 female administrators. However, even in the most central district which had the highest number of female administrators $(n=7)$, female administrators were mostly peripheral. Of the 12 peripheral female administrators in this network, eight (67\%) were peripheral due to having fewer ties or having ties to other administrators with fewer ties while only four $(33 \%)$ were peripheral within their districts due to having cross-district ties which pulled them closer to the other districts and away from central positions within their own districts. 


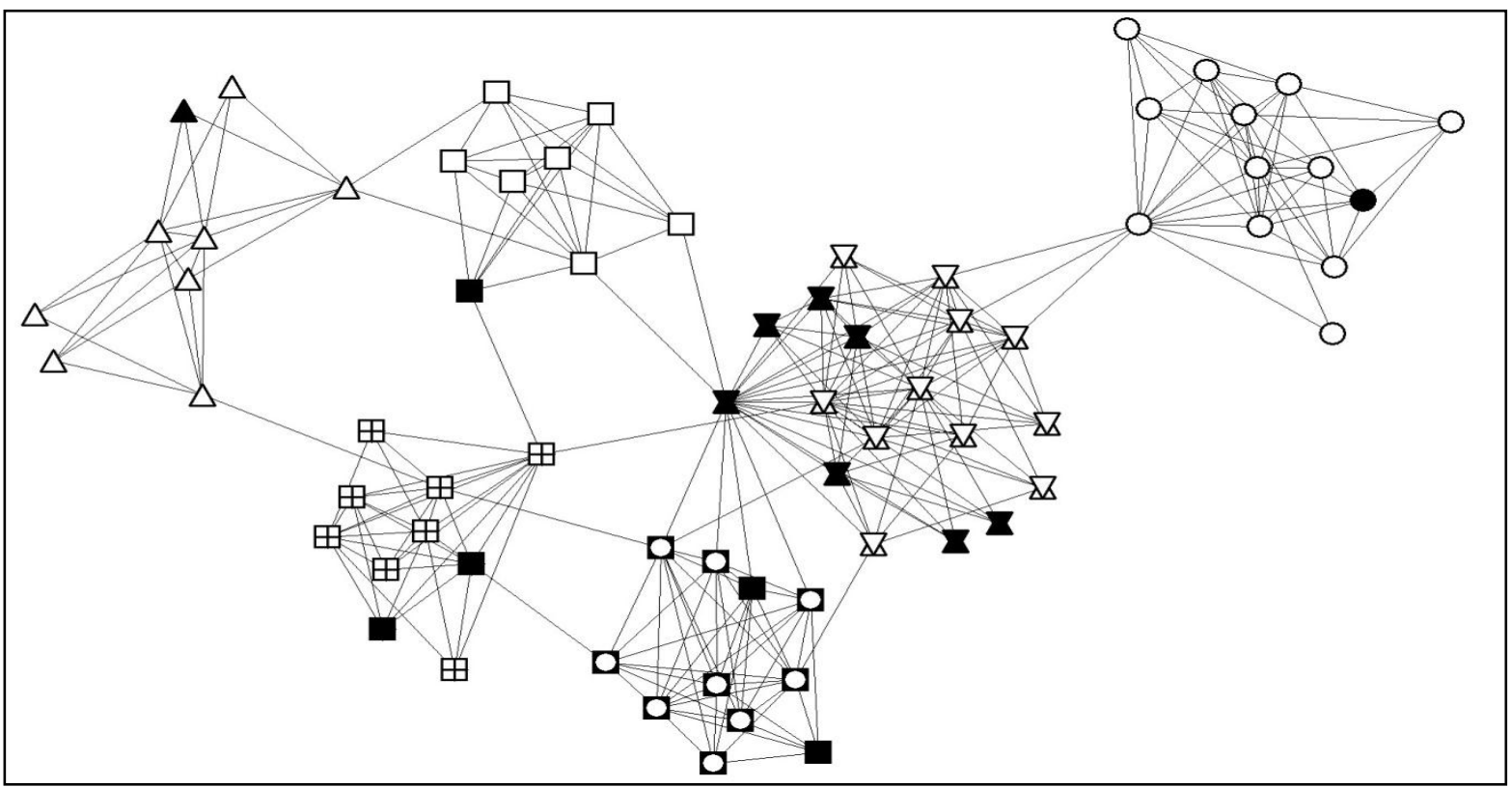

Figure 7. Inter-district administrative network: Relationally embedded ties by gender.

Key: Each district is represented by a different shape. Gender represented by color: male-white, female-black.

No clear patterns of within-district centrality emerged across the districts by the type of school setting within which the administrator functioned. The graphical network map in Figure 8 (retaining the district clustering as in Figure 6 and 7 and gender attributes as in Figure 7) uses size of the network node to represent each administrator's type of school setting (increasing in size from elementary school to middle school to high school to district office).

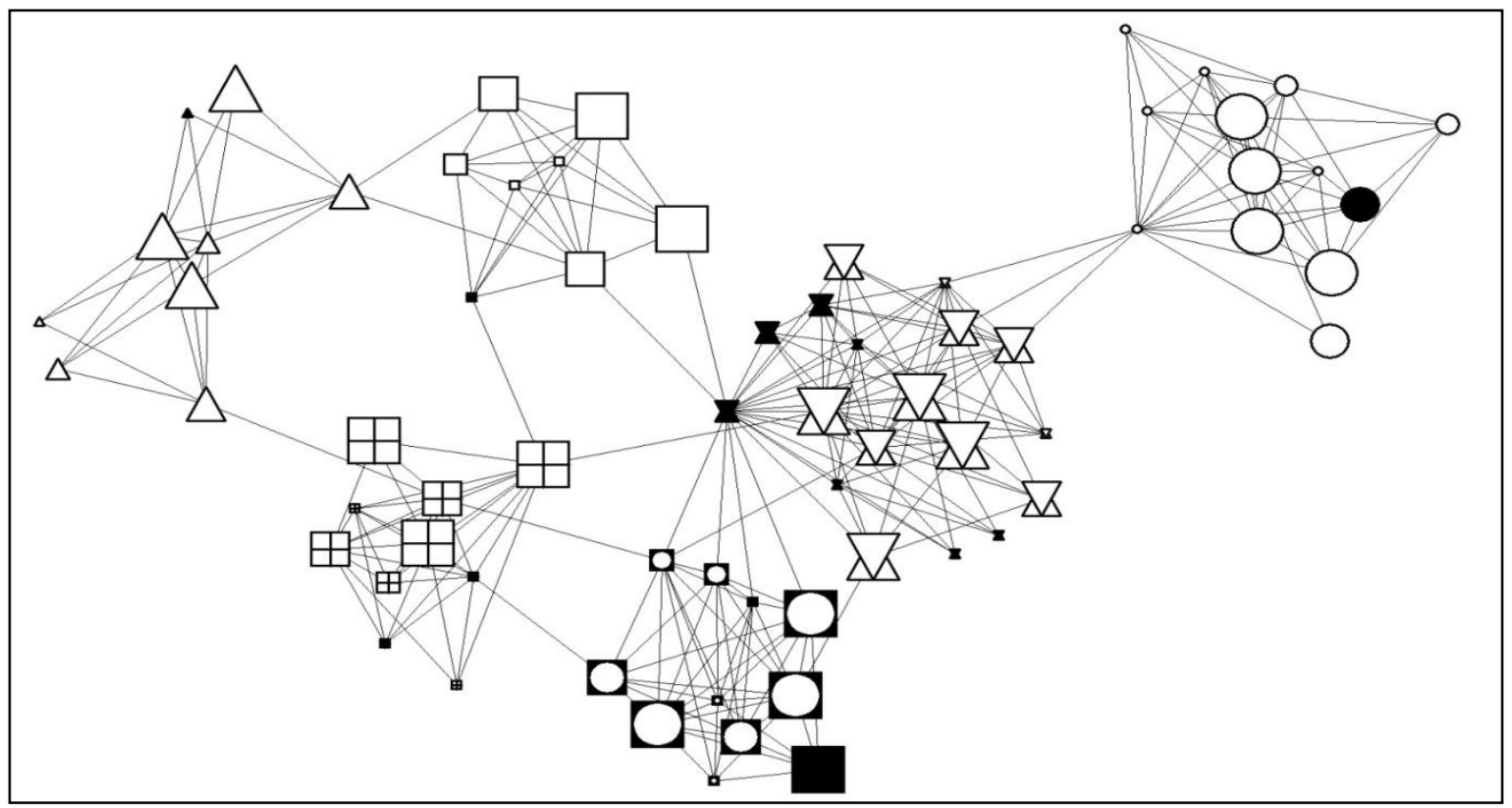

Figure 8. Inter-district administrative network: Relationally embedded ties by gender and type of school Key: District: icon shape. Gender: male-white, female-black. School type: icon size - elementary schools -small, middle schools- medium; high schools-large, district office -extra large. 
While district administrators are often considered to be central within their districts, this pattern was not clearly demonstrated in the network of relationally embedded ties. This finding may relate to the specific type of network content creating this structure. The only "type of school setting" pattern evident from Figure 8 is that many female administrators (64\%) were functioning in elementary schools.

A clear geographical pattern of relationally embedded ties emerged in the network graphs. The graphical maps in Figures $5-8$ are based on the social space created by the structure of the network ties. Yet these administrators were also located in actual geographical space. By displaying the intersection of this social and geographical space, with the administrators geographically positioned based on the latitude and longitude of their school, the structure of the administrator network assumes a somewhat different pattern (see Figure 9). The shaded lines represent general district boundaries, and schools are indicated in their actual geographical position by the small squares. Administrators were placed geographically at their schools such that their ties represent the schools' relationally-embedded ties to other schools or district offices within and across the districts. While each individual tie is represented with equal weight, multiple ties between administrators at the same schools overlap, accentuating certain geographical paths such that they appear darker. Topographical features and transportation routes are not indicated on this map for purposes of maintaining data confidentiality.

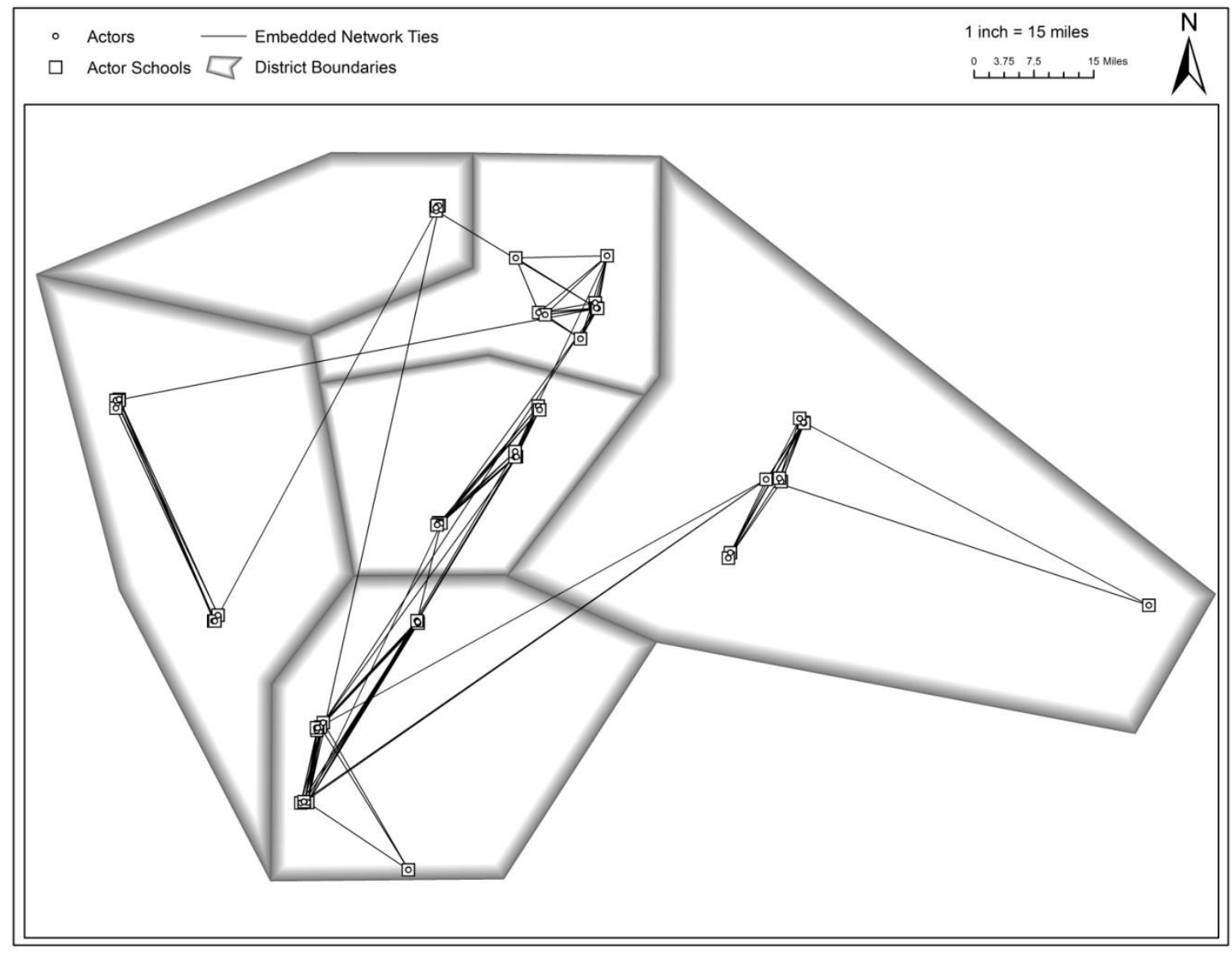

Figure 9. Intersection of social and geographical space: Geographically mapping the relationally embedded ties of six rural school district administrators. (Map created by Dr. Patrick R. Wawro.) 
A greater number of ties are evident along the main highway through this rural area (going from southwest to northeast). These ties span three main districts suggesting that easier transportation access may be a factor in developing the relational embeddedness of administrators in rural districts (Browne-Ferrigno \& Allen, 2006). Another geographical pattern to the network ties is found in the peripheral position of the eastern district in both social and geographic space, suggesting another interaction between these two dimensions.

Topographical maps of this area indicate that this eastern district is geographically separated from the other districts due to a mountain range with few access roads. Historically, culturally, and socially, the communities in this peripheral district have not actively interacted with the communities in the other districts, as is common in rural areas (e.g. BrowneFerrigno \& Allen, 2006). This network graph suggests that geographical space may influence the development of relationally embedded ties due to both proximity and ease of transportation. However, although the peripheral position of this district geographically is quite evident in the network of relationally embedded ties, when their ties with lower relational embeddedness, e.g. acquaintance and active work ties, are mapped into geographical space, this district is only slightly peripheral. One last pattern in the intersection of social and geographical space is that all of the schools have at least one relationally embedded tie with another school, and many have ties with schools in other districts.

\section{Discussion}

Understanding the structure and content of these administrative networks provides a beneficial perspective on the complexity within which leaders in rural education function (Sparrowe, et al., 2001). Findings suggest that the network structure and content of the administrative network in these rural school districts, both within and across districts, provide useful theoretical and strategic implications.

\section{Theoretical Implications}

The first theoretical implication of the findings is found in the interplay between network structure and its content. Different network sub-structures were identified for ties with different types of content. Relationally embedded ties had a clear pattern of within-district tie cohesion or density, while acquaintance ties and work ties were more evenly dispersed both within and across districts with no clear structural patterns. Thus ties with different content exhibit different network structures suggesting that the content may influence the resulting structure. This finding reflects the adage that form follows function or, in terms of organizations, that structure follows strategy (Chandler, 1962). This network structure also suggests that relational embeddedness, as a type of network content, may serve different purposes within and between these rural school districts.

While network theory suggests that structural cohesion and clustering would be expected among relationally embedded ties (Coleman, 1990; Moody \& White, 2003), this research sought to identify whether this clustering would occur within or between-districts. The propensity of relationally embedded ties between administrators in the same districts served to generate within-district clustering which aligned with the formal district structures. This finding may be explained given that administrators within a district have greater proximity, context similarity, and interdependence with each other than with administrators across districts. This cohesion may also be related to the tendency for rural districts to recruit and develop their administrators from within the districts (Browne-Ferrigno \& Allen, 2006). Recall the example of David and Charles, who were in the same district: Familiarity, personal interaction, shared context, and interdependence facilitated greater development of personal relationships, work interaction, and social capital. Thus, working in the same district, as opposed to being in different districts, may enhance the development of relational embeddedness. Therefore, the following proposition is supported from the findings:

\section{Proposition 1: In rural districts, relationally embedded ties are more likely to occur within district than between districts.}

This clustering of relationally embedded ties within the same district suggests benefits to rural school administration. Relationally embedded ties "have greater motivation to be of assistance and are typically more easily available" (Granovetter, 1983, p. 209). These ties would facilitate trust, shared problem solving, fine-grained information transfer, collaboration, innovation, and interactive learning (Borgatti \& Cross, 2003; J. M. Hite, 2003; Moran, 2005; Uzzi, 1996; Uzzi \& Lancaster, 2003). Future research should further examine further how rural school administrators develop relational embeddedness within their districts as well as how this internal cohesion of relational embeddedness can serve to benefit rural school districts. 
Relationally embedded ties were also found across the rural districts, although to a much lesser extent than within districts. These cross district ties highlight the potential strategic role of rural administrators in boundary spanning (Goldring, 1995). This network structure demonstrates how boundary spanning can create critical bridges and fill structural holes to enhance the flow network content (Burt, 2002). The position of a district on the periphery of the social network implies that less network content may be flowing to and from it; thus peripheral districts are likely to be more isolated from resource and information flows than more central districts (Borgatti, 2005). Among the districts participating in this study, the most peripheral district was connected to only one other district by only one administrator. This administrator is filling a clear structural hole in that without this administrator no ties would exist between this and the other districts (Burt, 1992b). In contrast, the other districts had more relationally embedded network ties to more districts, and these ties were spread among more brokers. Thus, these other districts would likely experience greater benefits from both more and higher quality network flows, such as resources, than the peripheral district.

Across these rural districts, however, boundary spanning functions were not limited to any particular administrative position, such as district administrators, suggesting that individual administrators can seek and create positive strategic advantages for their districts as they intentionally create ties to other districts and facilitate the evolution of these ties toward greater relational embeddedness (J. M. Hite, 2005).

The finding of fewer relationally embedded ties across than within districts aligns with the theory that weak ties, rather than relationally embedded ties, are more likely to "bridge social distance" and provide "access to information and resources beyond those available in their own social circles" (Granovetter, 1983, p. 209). The network of acquaintance and active work ties, which reflected the same structure as shown in Figure 5, highlights this concept given that the ties with lower, rather than greater, relational embeddedness were found more frequently across districts.

However, in contrast to these theoretical expectations, the study did identify that these districts each had between three and eight relationally embedded bridging ties to other districts. While this number is clearly fewer than their within-district relationally embedded ties, they are clearly present, more so than expected, and generate an observable level of cohesion by creating a fully connected network of districts. These across-district ties create the structure in which one district is clearly more central than the others, as a result of having the most ties with other districts (e.g. Scott, 2000). This district-level centrality means that one district would like be better positioned strategically to enjoy greater power, influence and resource and information flows (e.g. Borgatti, 2005; Pappas \& Wooldridge, 2007).

When bridging does occur through relationally embedded ties, these ties may provide additional strategic advantages for districts in terms of resource and information access (e.g. Granovetter, 1983). However, having a relationally embedded bridging tie may also have the effect of reducing individual administrators' centrality in their own district network structure, as they would be pulled into a more peripheral position, as can be seen in Figure 7 . This dynamic raises the question of potential strategic tradeoffs for administrators in their decisions regarding how to invest their network development resources. Given that developing and maintaining relationally embedded ties requires more time and effort (J. M. Hite, 2003), administrators may find it difficult to navigate the challenging balance of maintaining both types of relationally embedded ties, such that they can remain central within the district yet also function as a boundary spanner across districts. Therefore, the following proposition is suggested:

\section{Proposition 2: Within the network of relationally embedded ties in rural school districts, administrators with more relationally embedded ties that bridge across districts are more likely to have lower within- district centrality.}

Future research should seek to better understand why and how rural school administrators develop relationally embedded ties both within their own districts and across to other districts.

Another theoretical implication may also be drawn from the findings in terms of the role of gender. Given that female administrators were most often peripheral within their districts, administrator gender may be related to centrality within rural districts. Only one-third of these female administrators were peripheral due to boundary spanning, which would create a natural pull away from the center within their districts (Burt, 1992a; Scott, 2000). Thus, the question remains as to what other factors may influence their peripheral positions in the administrative network of relationally embedded ties. These peripheral positions may be explained by the nature of their administrative ties. 
These female administrators did not have as many relationally embedded ties within their districts as did the male administrators. Further analysis of the network data indicate, however, that this disparity also existed at the level of active work ties (although not at the level of acquaintance ties). Future research should continue to examine the nature and centrality effects of female administrator ties.

This study also has theoretical implications for how social space is influenced by the geographical nature of the work context (S. J. Hite et al., 2007), highlighting the role of geography on rural administrator networks. While the central and peripheral districts can be explained by their between-district ties, the development of these between-district ties may be informed by a geographical perspective. Of the six districts studied, the most peripheral district was also the most geographically isolated, separated from the other districts by mountainous terrain with few roads. While such geographical isolation is common for rural school districts (Arnold, Newman, Gaddy, \& Dean, 2005; Awalt \& Jolly, 1999), this study presents a unique view of how this geographical space influences the corresponding social space. In geographical contrast, the most central district, with the most between-district ties, was located along a major highway and contained most of the area's state educational services within its district boundaries. Thus, the geographical patterns of relationally embedded ties may be explained by ease of access in terms of transportation routes and geographical barriers that limit options for travel (BrowneFerrigno \& Allen, 2006). In addition, the relationally embedded ties of all six districts were located between-districts in close proximity. Thus, the centrality of rural school districts is suggested to correspond with clear geographical influences (S. J. Hite et al., 2007), as indicated in the following proposition:

\section{Proposition 3: Within the network of relationally embedded ties in rural school districts, district centrality will be influenced by geographical factors.}

Future research on the geographical isolation of rural schools and districts should also include relational perspectives for richer explanations of the extent and nature of resource flows to rural schools.

\section{Strategic Implications}

The structure and content of this network suggests several strategic implications for these rural education administrators and their districts. While network ties are developed and maintained between individual administrators, these administrators function as agents for their districts. Given that the structure and content of the set of administrative ties has strategic implications for a district, any discussion of strategic implications is, by nature, primarily focused at the district level of analysis. However, that being said, strategic implications have corresponding practical implications for individual administrators.

With only a few administrators in each district, rural districts have a strategic need for cross-district collaboration to access information, capabilities, and resources for effective school performance (Awalt \& Jolly, 1999). Rural administrators may find it to their advantage to understand how to create, manage and enhance cross-district networks. In addition, rural administrators and districts need to strategically choose where to invest in the development of their network ties, as these choices have strategic implications for the roles that administrators serve for their districts.

Both administrators and districts need to balance the distribution of relationally embedded ties such that the district can take advantage of both withindistrict cohesion as well as the bridging to other districts. District leaders may benefit from intentionally providing opportunities for their administrators to strengthen their within-district ties. This can result in more effective conduits within the district for the flow of information, resources and collaboration as well as create greater cohesion which can increase levels of trust between administrators. Given the high necessary investment in building relationally embedded ties, however, if administrators invest in developing a large number of within-district ties, they may not be as effective at building ties that bridge out into other districts. At the same time, if administrators seek to fill boundary spanning roles and strengthen their ties to other districts, they may be less able to maintain relationally embedded ties within their own district and thus lessen their internal centrality.

Yet another strategic implication of this study is that not all network ties need to be relationally embedded. For example, weak ties, such as nonrelationally embedded acquaintance and active work ties, can provide value in spanning structural holes across districts (Burt, 1992b; Granovetter, 1983). The majority of ties in this rural district network were not relationally embedded and they clearly spanned district boundaries (see Figure 5). Thus, districts may benefit from selectively investing in the development of relational embeddedness. 
Another strategic implication of this research is that the district's ability to find and acquire resources depends greatly upon its network. Because rural districts are smaller than their urban counterparts, they may have fewer available internal resources and strategic competencies. Districts may intentionally develop and use weaker network ties, with lower levels of relational embeddedness, to help compensate for resource deficiencies by creating bridges to other districts for finding new information, resources and opportunities for collaboration (Granovetter, 1973, 1983). However, actual resource acquisition is best facilitated by ties that have greater relational embeddedness (J. M. Hite \& Hesterly, 2001).

The practical implications of these findings for administrators can be seen in the example of the relationally embedded tie between David and Charles. If David and Charles were fellow administrators in the more peripheral district, they would be largely limited to within-district benefits given so few cross-district ties. They would have less access to resources and information from other districts and thus be more dependent on each other and on other administrators within their district. Yet, if both David and Charles were working together within a more central district, they could augment their within-district network benefits with the network benefits of those district administrators who function as cross-district brokers. Thus rural school districts may benefit from having administrators who fill both within- and cross-district network roles. If David and Charles were working as administrators in two different districts, their close friendship would enable them to function as brokers for their respective districts, creating a relationally embedded bridge across their districts. Such a bridge would benefit their respective districts, enabling the two districts to better collaborate, exchange resources and information, and learn from each other to solve problems.

\section{Future Research Directions}

Future research should continue to examine the network structures within and across rural school districts. First, given that this research examines only one set of six districts, the question remains as to whether the patterns found in this case are also found among other rural school districts. Second, given the finding of within-district cohesion for relationally embedded ties, how do administrators manage their centrality within this internal network and to what ends? Third, the role of relationally embedded ties as brokers across districts needs further examination.
Given that the literature suggests that brokering would be more likely to occur through weaker ties (e.g. Burt, 1992b), what are the advantages of relational embeddedness for brokering ties? Lastly, research should examine how rural administrators individually choose to balance the development of their relationally embedded ties. This choice to focus on internal cohesion versus bridging districts has clear career implications for these administrators.

This study has examined the structure and content of network ties, and demonstrates that rural school districts may benefit from greater strategic awareness of their own formal and informal networks, both within and across districts. This understanding may facilitate increased network development, monitoring, and maintenance to improve critical strategic administrative relationships that can benefit the improvement of student learning both at the district and school levels. Future research should examine the development and evolution of rural administrator networks and the relationship between these district network structures and district performance.

\section{Conclusion}

The social relationships among rural school administrators create larger network structures that can strategically influence the performance of administrators, schools, and districts (Moolenaar, et al., in press). This study examined the structure and content of the administrative network both within and across six rural school districts and identified potential strategic implications for their rural school administrators. The network structure of relationally embedded ties was distinctively different than that of the acquaintance and active work ties. It demonstrated a clear cohesion of relationally embedded ties within districts and fewer ties between districts. This network structure has implications for network centrality, boundary spanning and district resources. Both gender and geographical implications were also identified.

Administrators of rural education may find it to their advantage to better understand how to create and enhance both within- and across-district networks to help facilitate greater collaboration, information and resource flows and ultimately school performance (Awalt \& Jolly, 1999). By becoming more aware of the role of informal network relationships for school improvement, they can become more aware of the strategic implications of the larger network structures that result from the development of these critical administrative relationships (Snow, Miles, \& Coleman, 


\section{References}

Arnold, M. L., Newman, J. H., Gaddy, B. B., \& Dean, C. B. (2005). A look at the condition of rural education research: Setting a direction for future research. Journal of Research in Rural Education, 20(6), 1-25.

Awalt, C., \& Jolly, D. (1999). An inch deep and a mile wide: Electronic tools for savvy administrators. Educational Technology \& Society, 2(3), 97-105.

Bonacich, P. (1987). Power and centrality: A family of measures. American Journal of Sociology, 92, 11701182.

Borgatti, S. P. (2003). NetDraw. Natick, MA: Analytic Technologies.

Borgatti, S. P. (2005). Centrality and network flow. Social Networks, 27(1), 55-71.

Borgatti, S. P., Everett, M. G., \& Freeman, L. C. (1999). UCINet for Windows: Software for social network analysis. (Version 6.3). Natick, MA: Analytic Technologies.

Brass, D. J., Galaskiewicz, J., Greve, H. R., \& Tsai, W. P. (2004). Taking stock of networks and organizations: A multilevel perspective. [Review]. Academy of Management Journal, 47(6), 795-817.

Borgatti, S. P., \& Cross, R. (2003). A relational view of information seeking and learning in social networks. Management Science, 49(4), 432-445.

Borgatti, S. P., \& Foster, P. C. (2003). The network paradigm in organizational research: A review and typology. Journal of Management, 29(6), 991-1013.

Browne-Ferrigno, T., \& Allen, L. W. (2006). Preparing principals for high-need rural schools: A central office perspective about collaborative efforst to transform school leadership. Journal of Research in Rural Education, 21(1), 1-16.

Budge, K. (2006). Rural leaders, rural places: Problem, privilege, and possibility. Journal of Research in Rural Education, 21(13), 1-10.

Burt, R. S. (1992a). The social structure of competition. In N. Nohria \& R. G. Eccles (Eds.), Networks and organizations: Structure, form and action (pp. 57-91). Boston, MA: Harvard Business School Press.

Burt, R. S. (1992b). Structural holes: The social structure of competition. Cambridge, MA: Harvard University Press.

Burt, R. S. (2002). The social capital of structural holes. In M. F. Guillén, R. Collins, P. England \& M. Meyer (Eds.), New Directions in Economic Sociology ( pp. 201-251). New York: Russell Sage Foundation.

Carrington, P., \& Scott, J. ( in press). The Sage handbook of social network analysis. Thousand Oaks, CA: Sage.

Chandler, A. D., Jr. (1962). Strategy and structure: Chapters in the history of the industrial enterprise. Cambridge, MA: MIT Press.
Coleman, J. S. (1990). Foundations of social theory. Cambridge, MA: Harvard University Press.

Costenbader, E., \& Valente, T. W. (2003). The stability of centrality measures when networks are sampled. Social Networks, 25, 283-307.

Daly, A. J., \& Finnigan, K. S. (2010). A bridge between worlds: Understanding network structure to understand change strategy. Journal of Education Change, 11(2), 111-138.

Dyer, J. H., \& Singh, H. (1998). The relational view: Cooperative strategy and sources of interorganizational competitive advantage. Academy of Management Review, 23(4), 660-679.

Elfring, T., \& Hulsink, W. (2007). Networking by entrepreneurs: Patterns of tie formation in emerging organizations. [Network, theory]. Organization Science, 28(12), 1849-1872.

Friedkin, N. E., \& Slater, M. R. (1994). School leadership and performance: A social network approach. Sociology of Education, 67(2), 139-157.

Furtwengler, B., Furtwengler, C., Turk, R., \& Hurst, D. (1997). Small school districts: Networks of collaborators. The Rural Educator, 19(1), 25-29.

Goldring, E. B. (1995). Striking a balance: Boundary spanning and environmental management in schools. In S. B. Bacharach \& B. Mundell (Eds.), Images of schools: Structures and roles in organizational behavior (pp. 283-314). Thousand Oaks, CA: Corwin Press.

Granovetter, M. S. (1973). The strength of weak ties. American Journal of Sociology, 78(6), 1360-1380.

Granovetter, M. S. (1983). The strength of weak ties: A network theory revisited. In P. V. Marsden \& N. Lin (Eds.), Social structure and network analysis (pp. 105130). Beverly Hills, CA: Sage.

Granovetter, M. S. (1985). Economic action and social structure: The problem of embeddedness. American Journal of Sociology, 91(3), 481-510.

Granovetter, M. S. (1986). The micro-structure of school desegregation. In J. Prager, D. Longshore \& M. Seeman (Eds.), School desegregation research: New directions in situational analysis (pp. 81-110). New York: Plenum Press.

Granovetter, M. S. (1992). Problems of explanation in economic sociology. In N. Nohria \& R. Eccles (Eds.), Networks and organizations (pp. 25-56). Boston: Harvard Business School Press.

Gulati, R. (1995). Does familiarity breed trust? The implications of repeated ties for contractual choice in alliances. Academy of Management Journal, 38(1), 85113. 
Hannerman, R.A., \& Riddle, M. (2005).Introduction to social network methods. Riverside, CA: Retrieved October 7, 2010, from http://faculty.ucr.edu/ hanneman/nettext/

Harmon, H. L., \& Schafft, K. (2009). Rural school leadership for collaborative community develoment. The Rural Educator, 30(3), 4-9.

Hite, J. M. (2003). Patterns of multi-dimensionality among embedded network ties: A typology of relational embeddedness in emerging entrepreneurial firms. Strategic Organization, 1(1), 9-49.

Hite, J. M. (2005). Evolutionary processes and paths of relationally-embedded network ties in emerging entrepreneurial firms. Entrepreneurship Theory and Practice, 29(1), 113-144.

Hite, J. M. (2008). The role of dyadic multidimensionalityin the evolution of strategic network ties. In J.A.C. Baum, \&T.J. Rowley (Eds.), Advances in strategic management: Network strategy (Vol. 25, pp. 133-170). Oxford, UK: Emerald..

Hite, J. M., \& Hesterly, W. S. (2001). The evolution of firm networks: From emergence to early growth of the firm. Strategic Management Journal, 22(3), 275-286.

Hite, J. M., Williams, E. J., \& Baugh, S. B. (2005). Multiple networks of public school administrators: An analysis of network content and structure. International Journal of Leadership in Education, 8(2), 91-122.

Hite, J. M., Williams, E. J., Hilton, S. C., \& Baugh, S. C. (2006). The role of administrator characteristics on perceptions of innovativeness among a network of public school administrators. Education and Urban Society, 38(2), 160-187.

Hite, S. J., Hite, J. M., Mugimu, C. B., \& Rew, W. J. (2007). Geographic space and social space: A statistical analysis of Euclidean, actual, and least-cost distance and network ties of headteachers in Uganda. . Paper presented at the International Workshop on Social Space and Geographic Space - SGS'07, Melbourne Business School, Victoria, Australia.

Hoang, H., \& Antoncic, B. (2003). Network-based research in entrepreneurship: A critical review. Journal of Business Venturing, 18(2), 165-187.

Honig, M. I. (2006). Street-level bureaucracy revisited: Frontline district central-office administrators as boundary spanners in education policy implementation. Educational Evaluation and Policy Analysis, 28(4), 357-383.

Ibarra, H. (1992). Structural alignments, individual strategies and managerial action: Elements toward a network theory of getting things done. In N. Nohria \& R. G. Eccles (Eds.), Networks and organizations: Structure, form and action (pp. 165-188). Boston, MA: Harvard Business School Press.

Ibarra, H. (1993). Network centrality, power, and innovation involvement: Determinants of technical and administrative roles. Academy of Management Journal, 36(3), 471-501.

Kahne, J., O'Brien, J., Brown, A., \& Quinn, T. (2001). Leveraging social capital and school improvement: The case of a school network and a comprehensive community initiative in Chicago. Educational Administration Quarterly, 37(4), 429.

Kilduff, M., \& Tsai, W. (2003). Social networks and organizations (1st ed.). London: Sage.

Krackhardt, D., \& Hanson, J. R. (1993). Informal networks: The company behind the chart. Harvard Business Review, 71(4), 104-111.

Mizruchi, M. S., \& Galaskiewicz, J. (1993). Networks of interorganizational relations. Sociological Methods and Research, 22(1), 46-70.

Moody, J. (2001). Race, school integration, and friendship segregation in America. The American Journal of Sociology, 107(3), 679-717.

Moody, J., \& White, D. R. (2003). Structural cohesion and embeddedness: A hierarchical conception of social groups. American Sociological Review, 68(1), 103-127.

Moolenaar, N. M., Daly, A. J., \& Sleeters, P. J. C. (in press). Occupying the principal position: Examining relationships between transformational leadership, social network position, and schools' innovative climate. Educational Administration Quarterly.

Moran, P. (2005). Structural vs. relational embeddedness: Social capital and managerial performance. Strategic Management Journal, 26(12), 1129-1151.

Pappas, J. M., \& Wooldridge, B. (2007). Middle managers' divergent strategic activity: An investigation of multiple measures of network centrality. Journal of Management Studies, 44(3), 323-341.

Raider, H., \& Krackhardt, D. (2002). Intraorganizational networks. In J. A. C. Baum (Ed.), The Blackwell companion to organizations (pp. 58-74). Oxford, UK: Blackwell.

Scott, J. (2000). Social network analysis (2nd ed.). London: Sage.

Snow, C. C., Miles, R. E., \& Coleman, H. J. J. (1992). Managing 21st century network organizations. Organizational Dynamics, 20(3), 5-20.

Sparrowe, R. T., Liden, R. C., Wayne, S. J., \& Kraimer, M. L. (2001). Social networks and the performance of individuals and groups. Academy of Management Journal, 44(2), 316-325.

Tsai, W. (2001). Knowledge transfer in intraorganizational networks: Effects of network position and absorptive capacity on business unit innovation and performance. Academy of Management Journal, 44(5), 996-1004.

Uzzi, B. (1996). The sources and consequences of embeddedness for the economic performance of organizations: The network effect. American Sociological Review, 61(4), 674-698. 
Uzzi, B., \& Lancaster, R. (2003). Relational embeddedness and learning: The case of bank loan managers and their clients. Management Science, 49(4), 383-399.

Wasserman, S., \& Galaskiewicz, J. (1994). Advances in Social Network Analysis: Research in the Social and Behavioral Sciences. Thousand Oaks: Sage.
Wohlstetter, P., Malloy, C. L., Chau, D., \& Polhemus, J. L. (2003). Improving schools through networks: A new approach to urban school reform. Educational Policy, 17(4), 399-431.

Julie M. Hite, Ph.D. (julie hite@ byu.edu) is an Associate Professor in Educational Leadership and Foundations at Brigham Young University. Her research focuses on strategic organizational networks and school performance.

Dr. Bart Reynolds, an Assistant Professor of Graduate Studies in Education at Southern Utah University, and currently serves as the Director of Educational Leadership.

Steven J. Hite is professor of educational research theory and methodology at Brigham Young University. His work focuses on improving educational opportunities for disadvantaged individuals, families and communities globally. 